\title{
Herbal Medicines for Hepatitis C Virus Infection: The Exploratory Journey from Bench to Bedside Still Has a Long Way to Go
}

\author{
Xiao-Ya Yang1,\#, Yuan-Yuan Zhang,"\#, Wen-Rui Xie ${ }^{3}$, Selin Hua $\mathrm{He}^{4}$, Li-Hao $\mathrm{Wu}^{3}$, \\ Xing-Xiang $\mathrm{He}^{3}$ and Harry Hua-Xiang $\mathrm{Xia}^{3 *}$
}

\begin{abstract}
${ }^{1}$ Department of Physiology, Guangzhou Health Science College, Guangzhou, China; ${ }^{2}$ Department of Pharmacology, West China School of Basic Medical Sciences and Forensic Medicine, Sichuan University, Chengdu, China; ${ }^{3}$ Department of Gastroenterology, The First Affiliated Hospital of Guangdong Pharmaceutical University, Guangzhou, China; ${ }^{4}$ Institute for

Viral Hepatitis, Key Laboratory of Molecular Biology for Infectious Diseases, Ministry of Education, Chongqing Medical University, Chongqing, China; ${ }^{\#}$ Contributed equally.
\end{abstract}

\begin{abstract}
Hepatitis $\mathrm{C}$ virus (HCV) infects at least 150 million people chronically worldwide. It is a major risk factor for cirrhosis, hepatocellular carcinoma, and death. Direct-acting antiviral therapy is very efficacious in treating HCV infection but it is inaccessible and unavailable in some developing countries. Therefore, searching for more effective and easily accessible regimens remains an urgent need. The aim of this article is to review the anti-HCV effects of herbal medicines from experimental to clinical evidence, and discuss current issues, hurdles and future perspectives for their application from bench to bedside. Numerous in vitro studies have indicated that many herbs work effectively in exerting anti-HCV activities. Yet, only a few animal experiments have been conducted that demonstrate the anti-HCV effects of these medicines; in addition, these results do not show an ability to eliminate the virus completely from the infected animals. Thus far, clinical trials have produced inconclusive anti-HCV results in terms of efficacy and safety, presumably due to the lack of the quality of methodologies used in the trials. In conclusion, despite apparent anti-HCV activities in vitro, clinical efficacy and safety of herbal medicines for the treatment of HCV infection have not been revealed convincingly. More animal studies using ideal models and more well-designed clinical trials with a larger sample sizes and longer treatment periods, taking the body habitus into consideration, are required to further assess the efficacy and safety of herbal medicines for HCV infection.
\end{abstract}

Introduction

Hepatitis $\mathrm{C}$ virus $(\mathrm{HCV})$ is an enveloped and positive strand RNA virus of the Hepacivirus genus within the Flaviviridae family. ${ }^{1}$ $\mathrm{HCV}$ chronically infects at least 150 million people worldwide, especially in central Asia and the Mediterranean, having prevalence of $>3.5 \%)^{2,3}$ More than $60 \%$ of acutely infected patients

Keywords: Herbal medicine; Hepatitis C virus; Efficacy; Safety.

Abbreviations: AE, adverse event; ALT, alanine transaminase; AST, aspartate aminotransferase; $\mathrm{CHC}$, chronic hepatitis C; DAA, direct-acting antiviral agent; ETVR, end-of-treatment viral response; GGT, $\gamma$-glutamyl transferase; GOT, glutamate oxaloacetate transaminase; GPT, glutamate pyruvate transaminase; HCV, hepatitis C virus; Peg-IFN, pegylated-interferon alpha-2a; RCT, randomized controlled trials; SVR, sustained virological response; XCHT, Xiao-Chai-Hu-Tang.

Received: May 26, 2019; Revised: June 18, 2019; Accepted: June 24, 2019

*Correspondence to: Harry Hua-Xiang Xia, Department of Gastroenterology, The First Affiliated Hospital of Guangdong Pharmaceutical University, 19 Nonglinxia Road, Guangzhou 510080, Guangdong Province, China. Tel: +86 18802730710; Email: xiaharry@hotmail.com

How to cite this article: Yang X-Y, Zhang Y-Y, Xie W-R, He SH, Wu L-H, He X-X, Xia HH-X. Herbal Medicines for Hepatitis C Virus Infection: The Exploratory Journey from Bench to Bedside Still Has a Long Way to Go. J Explor Res Pharmacol 2019;4(2):9-18. doi: 10.14218/JERP.2019.00003. suffer from chronic HCV infection, which develops into cirrhosis in $5-25 \%$ of the infected patients within 25-30 years. Moreover, approximately $30 \%$ of cirrhotic patients develop decompensated liver disease within 10 years, and $1-3 \%$ of them develop hepatocellular carcinoma eventually. ${ }^{1,4}$ Thus, HCV infection is one of the major global health problems.

Herbal medicines, which have been used to treat various diseases for thousands of years, especially in traditional Chinese medicine, have become a main component of complementary medicine in the West. ${ }^{5}$ Various herbal medicines, including formula, extracts and compounds derived from herbs, have been used for treatment of liver diseases, including chronic hepatitis $\mathrm{B}$, chronic hepatitis $\mathrm{C}(\mathrm{CHC})$, alcoholic liver disease, and nonalcoholic fatty liver disease. ${ }^{6-11}$ Over the past few decades, particular attention has been paid to the potential anti-HCV effects of herbal medicines, and most of in vitro (in hepatic cell lines) and in vivo (in animals) studies have shown significant anti-HCV effects for a number of herbal medicines.

To evaluate the clinical efficacy and safety of herbal medicines in patients with $\mathrm{CHC}$, many clinical studies, including randomized controlled trials (RCTs), have been carried out. Although herbal medicines perform well in reducing risk of liver cirrhosis and overall mortality in the patients with $\mathrm{HCV},{ }^{12}$ their clinical efficacy, in 
terms of clearance of serum HCV RNA, remains inconclusive. In this article, we review the anti-HCV effects of herbal medicines from experimental to clinical evidence, and discuss the current issues and hurdles, and future perspectives for their application from bench to bedside.

\section{Current treatment for $\mathrm{HCV}$ infection}

HCV life cycle includes the entry of HCV particle into hepatocytes, translation and replication of HCV RNA, and assembly, budding and secretion of HCV. ${ }^{13,14}$ The HCV genome is approximately $9.6 \mathrm{~kb}$ of uncapped RNA. ${ }^{15}$ The HCV RNA encodes a polyprotein, which is processed by host and viral proteases into at least 10 products. These products include structural proteins, such as Core, E1 and E2, and nonstructural proteins, such as NS2, NS3, NS4A, NS4B, NS5A and NS5B. ${ }^{15}$ All the nonstructural polypeptides are potential targets for drug therapy.

Treatment of HCV infection is experiencing rapid progress. Before the advent of the direct-acting antiviral agent (DAA), including inhibitors of polymerase, NS5A and protease, pegylated interferon (peg-IFN) and ribavirin were considered as the standardof-care treatment, yielding sustained virological response (SVR) rates of approximately $50 \%$ for genotype 1 patients. ${ }^{16,17}$ The firstgeneration protease inhibitors boceprevir and telaprevir were approved in 2011. Triple regimens with boceprevir or telaprevir, plus peg-IFN and ribavirin initiated the era of DAA therapy, ${ }^{18,19}$ with SVR rates of $67-75 \%$ for naïve patients. However, the development of resistance-associated virus variants and severe adverse events (AEs) restricted this triple therapy regimen.

For the polymerase inhibitors (e.g., sofosbuvir and dasabuvir), the new-generation drugs (e.g. simeprevir and grazoprevir) and NS5A inhibitors (e.g. ledipasvir and velpatasvir) were approved soon after. IFN-free combination regimens, consisting of one to two DAAs from different classes based on the HCV genotype with or without ribavirin, had been recommended as the first-line standard-of-care treatment for CHC in European countries up to 2017. ${ }^{20}$ Due to the virological efficacy (high SVR rates, up to 90\%), safety and tolerability, the European Association for the Study of the Liver recommended in 2018 an IFN-free, ribavirin-fee, DAA-based regimens as the preferred options for treating $\mathrm{HCV}$-infected patients without cirrhosis or with compensated cirrhosis. ${ }^{21}$ Therefore, DAA therapy has been verified to be very efficacious for HCV infection; however, in many developing regions of the world, $\mathrm{HCV}$ remains uncontrolled due to inaccessibility and unavailability of DAA-based regimens. ${ }^{3,22}$ Therefore, searching for more effective and easily accessible regimens remains an urgent need.

\section{Experimental evidence of herbal medicines against $\mathrm{HCV}$}

\section{In vitro studies}

A number of in vitro studies have been carried out to identify the herbal medicines with effective anti-HCV activity. A multitude of herbal medicines, including extracts and formulas, have demonstrated anti-HCV effects. The effects and mechanisms by which these herbal medicines inhibit HCV infection are listed in Table 1. ${ }^{23-51}$ According to the modes of action, we have classified, here, these anti-HCV herbal medicines into three forms: (1) NS protein inhibition; (2) HCV entry inhibition; and (3) others, as described below.
NS protein inhibition

Methanolic extracts of Acacia nilotica, Boswellia carterii, Embelia schimperi, Quercus infectoria, Trachyspermum ammi, ${ }^{23}$ Phyllanthus amarus and Terminalia arjuna, ${ }^{24}$ water extracts of Piper cubeba, Q. infectoria, Syzygium aromaticum and Embeliaribes, ${ }^{23,25}$ ethanol extracts of Rhodiola kirilowii (Regel) Maxim, ${ }^{26}$ Saxifraga melanocentra and Spatholobus suberectus, ${ }^{27,28}$ and other extracts of Galla Chinese, ${ }^{29}$ Magnolia officinalis (Hou-Pu) and Solanum nigrum seeds all have shown inhibitory effects on the NS3 protease, ${ }^{30,31}$ while ethanol extract of $V$. Vinifera root has shown inhibitory effect on the NS3 helicase. All of those extracts demonstrated potent reduction of HCV RNA concentration. Besides NS3, NS5B is another dominating target. Extracts of Phyllanthus amarus and Terminalia arjuna, ${ }^{24}$ Fructus Ligustri Lucidi and Aeginetiaindica have been shown to exert their anti-HCV effects through inhibition of the NS5B polymerase. ${ }^{32,33}$ In addition, the NS3/4A protease, NS4A and NS5A protein have been verified as the anti-HCV targets of Azadirachta indica leaves, ${ }^{34}$ Piper cubeba, Q. infectoria, Syzygium aromaticum, ${ }^{23}$ Magnolia officinalis (Hou-Pu), ${ }^{30}$ Spatholobus suberectus and seeds of Silybum marianum, ${ }^{28,35}$ respectively.

HCV entry inhibition

As the multistep process of HCV entry into host cells, HCV entry becomes an important target of anti-HCV activities (i.e. its impediment). Examples of herbal medicines targeting for inhibition of $\mathrm{HCV}$ entry include methanolic extracts of Bupleurum kaoi root, ${ }^{36}$ Morinda citrifolia and Rhizoma coptidis, ${ }^{37,38}$ ethanol extracts of fruits of Schisandra sphenanthera Rehd. et Wils, ${ }^{39}$ water extracts of wild Egyptian artichoke, ${ }^{52}$ and other extracts of Dipsacus asperoides, ${ }^{40}$ Magnolia officinalis $(\mathrm{Hou}-\mathrm{Pu}){ }^{30}$ and compounds of epigallocatechin-3-gallate, delphinidin, ${ }^{41}$ flavone and flavanbased compounds (amentoflavone, 7,40-dihydroxyflavanone, and orobol). ${ }^{42}$

Others

NS protein inhibition and HCV entry inhibition are the two main anti-HCV modes of herbal medicines. Beyond those, Nigella sativa seed, ${ }^{43}$ Cinnamomi cortex, ${ }^{44}$ and flavone and flavan-based compounds (amentoflavone, 7,40-dihydroxyflavanone, and orobol) have been shown to exert their anti-HCV actions by inhibiting HCV replication. ${ }^{42}$ In addition to inhibiting HCV entry at the post-binding stage, Qian et al. ${ }^{39}$ found that schizandronic acid from ethanol extracts of fruits of Schisandra sphenanthera Rehd. et Wils impeded HCV infection by other mechanisms, including inhibition of internalization of the viral particles and blockage of intercellular spread to neighboring cells. The 7-O-methylated analogues of flavonolignans from Silybum marianum have been reported to prevent $\mathrm{HCV}$ infection by inhibiting drug metabolizing enzymes (CYP2C9, CYP3A4/5, and UDP-glucuronosyltransferases), ${ }^{45}$ while another bioactive compound from seeds of Silybum marianum, silymarin (MK-001) has been shown to inhibit HCV by enhancing the Jak-STAT signaling pathway. ${ }^{35}$

\section{Animal experiments}

Although a number of in vitro studies have been conducted for 


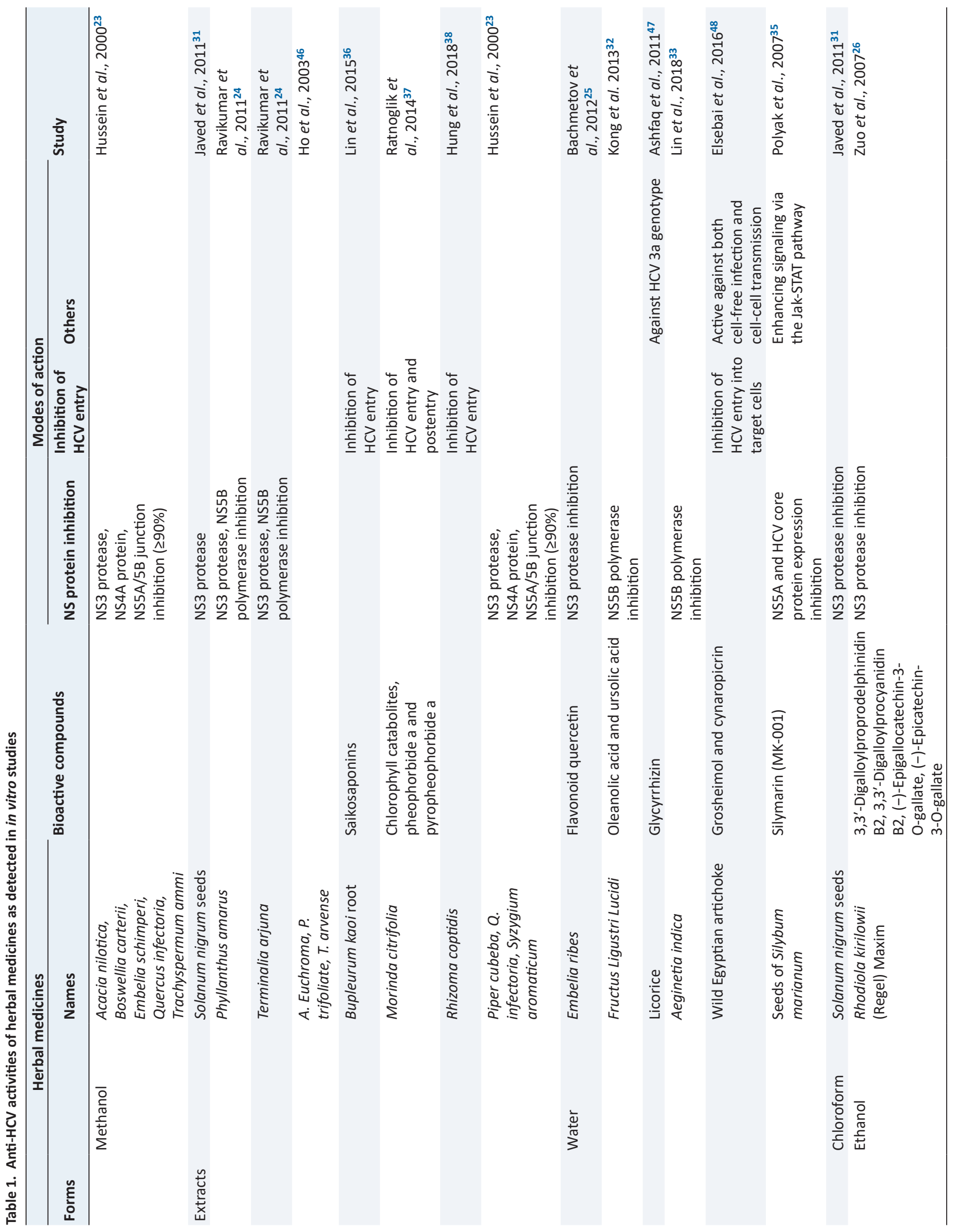




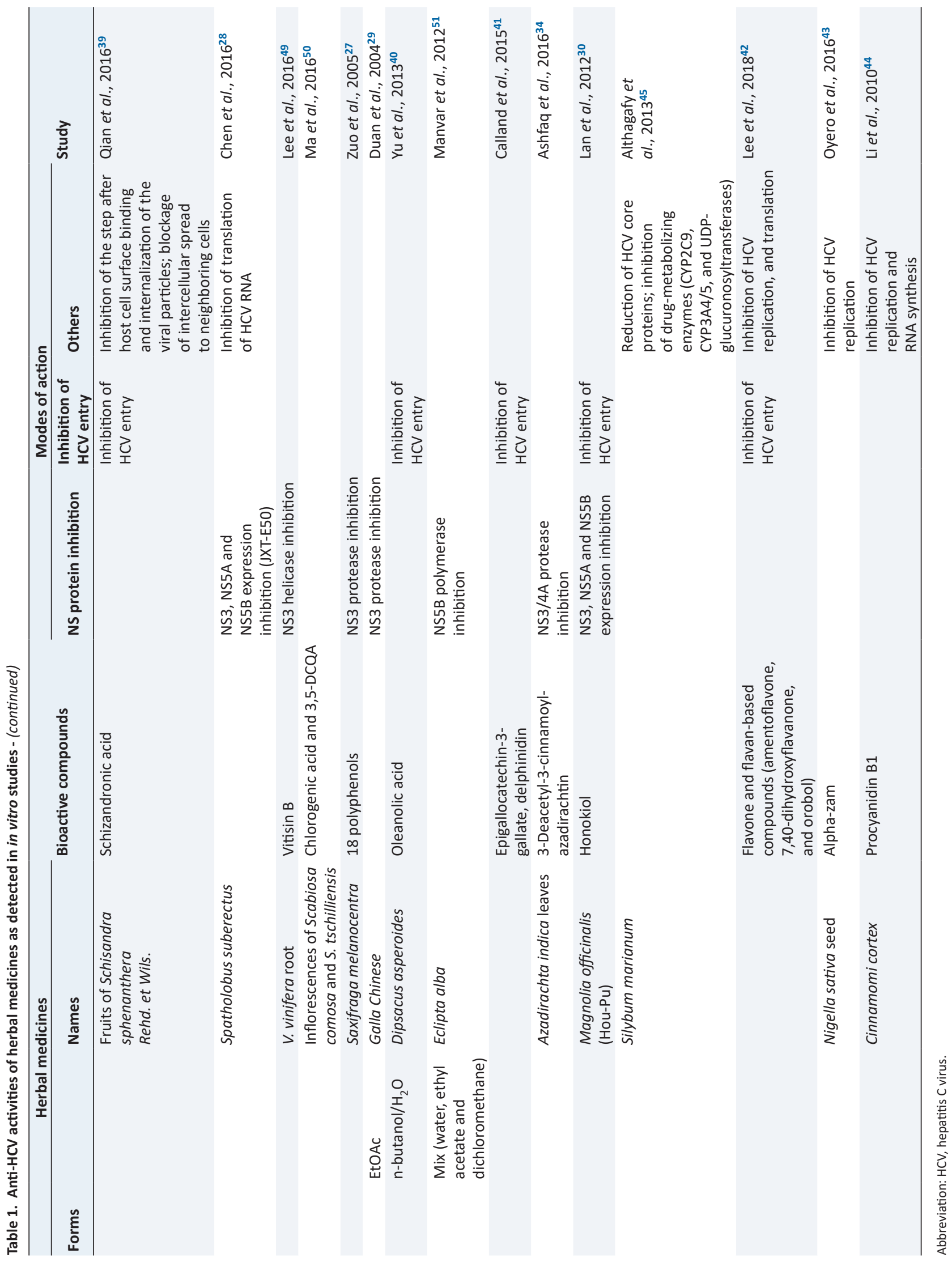


numerous herbal medicines, only two studies were carried out to assess their anti-HCV effects in animals. ${ }^{39,53}$

Qian et $a l .{ }^{34}$ used the transgenic ICR mice harboring human $S R B 1, C D 81, C L D N 1$ and $O C L N$ genes to investigate the anti$\mathrm{HCV}$ effects of schizandronic acid, which had been extracted from fruits of Schisandra sphenanthera Rehd. et Wils. They observed that HCV RNA levels in the serum were reduced in transgenic ICR mice treated with schizandronic acid for 2 weeks, with less positive HCV NS3 or core protein in hepatocytes, indicating the anti$\mathrm{HCV}$ effects of schizandronic acid in vivo. However, the elimination of HCV infection in the infected mice was incomplete. ${ }^{39}$

Tang et al..$^{53}$ tested 20 Chinese herbs in nude mice to determine their anti-HCV effects. They found that Radix Gentianae (Long Dan Cao), Radix Scutellariae (Huang Qin), Radix Sophoraetonkinensis (Shan Dou Gen), Fructus Gardeniae (ZhiZi) and Fructus Sophorae flavescentis (Ku Shen) significantly inhibited the replication of HCV-RNA. Similar to the observation in the above study, none of them completely eliminated HCV from the infected mice.

Therefore, although both animal studies demonstrated anti$\mathrm{HCV}$ effects of the herbal medicines studied, none of them were able to completely eliminate HCV from the infected animals.

\section{Clinical evidence of herbal medicines against HCV}

Herbal medicines have long been used worldwide for the treatment of CHC. Most studies have shown that herbal medicines can attenuate liver-related symptoms, ${ }^{54}$ improve liver functions and quality of life, ${ }^{55}$ prolong the progression from fibrosis to cirrhosis, ${ }^{56,57}$ and reduce or prevent AEs such as anemia and psychiatric complications. ${ }^{58,59}$ Some herbal medicines have been evaluated for their anti-HCV effects in patients with $\mathrm{CHC}$ in clinical trials, including nonrandomized and randomized trials. ${ }^{54,60,61}$ Due to the overall low methodological quality of the nonrandomized trials, in this review we only describe the efficacy and safety of herbal medicines in patients with $\mathrm{CHC}$ that were evaluated in RCTs, in order to provide objective and reliable data.

A number of clinical studies have been carried out to compare the efficacy and safety between herbal therapy alone or in combination with IFN-therapy and antiviral therapy (with IFN or other agents), nonspecific nonantiviral therapy, or placebo for the treatment of CHC. In these studies, SVR (i.e. the lack of detectable HCV RNA in serum, representing loss of serum HCV RNA, by a sensitive test at 6 months after treatment cessation), end-of-treatment viral response (ETVR; i.e. undetectable HCV RNA at the end of treatment), relapse rate (i.e. the proportion of cases with undetectable HCV RNA at the end of treatment but detectable HCV RNA 24 weeks posttreatment), alanine transaminase (ALT) normalization, and/or occurrence of AEs were used as the outcome end-points.

\section{General overview of clinical trials}

Although experimental evidence has exhibited encouraging anti$\mathrm{HCV}$ effects of herbal medicines, clinical trials have produced inconclusive anti-HCV results in terms of efficacy and safety, presumably due to the lack in quality of methodologies used in the trials.

Qin et al.$^{60}$ performed a meta-analysis of 51 RCTs carried out between 1993 and 2008. They showed that Chinese herbal medicines achieved a better virological response, including loss of serum HCV RNA, than nonspecific or placebo treatments, and appeared to have an clinical efficacy equal to IFN treatment, in terms of symptoms, liver function, and virological response. In addition, a combination of herbal medicine and IFN resulted in better liver function improvement and virological response than antiviral treatment alone. Serious (S)AEs have been rarely reported for patients who underwent herbal treatment. ${ }^{60}$ These findings suggest that herbal medicines have effects in improving symptoms, liver function, and loss of HCV markers in HCV patients, with good safety profiles, and thus have potential for the clinical application to $\mathrm{CHC}$ patients. However, it should be emphasized that, as Qin et al. revealed, all RCTs included in this meta-analysis (published in Chinese) suffered from poor methodological quality, and thus the findings of this meta-analysis need to be confirmed in more rigorous clinical trials.

In 2011, Zhao et al. ${ }^{61}$ reported a meta-analysis of RCTs that were carried out between 2001 and 2010 and which had at least 24-week treatment periods, to compare the clinical efficacy and safety of Chinese herbal therapy alone with that in combination with IFN therapy, and IFN therapy alone for the treatment of patients with CHC. They reported that, compared with IFN therapy alone, Chinese herbal therapy alone presented a lower relapse rate as well as a lower ETVR rate. However, a combination of IFN and Chinese herbal therapies yielded higher ETVR and SVR rates, a lower relapse rate, and more rapid ALT normalization, with fewer AEs than IFN therapy alone. These results suggest that although Chinese herbal therapy alone does not show significant anti-HCV effects compared to IFN therapy alone, it may play an additional or even synergistic role in the combined therapies. Obviously, this later meta-analysis provides more compelling data on the efficacy of herbal medicines, especially in combination with IFN-therapy. Again, these results should also be taken with caution due to the quality issues mentioned above. There has been no confirmatory and convincing clinical evidence so far to demonstrate any efficacy of any herbal medicines, in terms of SVR and ETVR.

\section{Recent advances in clinical trials of four herbs}

Despite the inconclusive outcomes from clinical trials, the exploratory journey searching for herbal medicines that are effective both in vitro and in clinical practice has never stopped. Currently, several herbal medicines with clinical potential are under investigation. Here, we summarize some recent advances in clinical trials of four herbs, with preliminary but encouraging results (Table $2^{62-65,67-70,76}$ ).

\section{Silymarin}

Silybum marianum shows impressive anti-HCV effects in the experimental studies, as described above. This natural herb has been used as a liver tonic for hundreds of years, and recently for the treatment of CHC. Disappointingly, most clinical trials failed to get the results expected according to those from the experimental studies. No clinically meaningful reduction in HCV RNA level was observed upon administration of $S$. marianum or silymarin (a substance derived from $S$. marianum) orally, from customary doses to high doses, and serum ALT and/or aspartate transaminase (AST) levels were not decreased in most of the studies. ${ }^{62-67}$ Encouragingly, in 2013, Mariño et al.$^{68}$ and Bárcena et al. ${ }^{69}$ conducted intravenous monotherapy with silibinin (the major compound of silymarin) in $\mathrm{HCV}$-infected patients awaiting liver transplantation; the treatment led to significant and progressive HCV RNA decreases. This finding indicates that silibinin acts as the most potent compound of silymarin and intravenous administration is a better way 


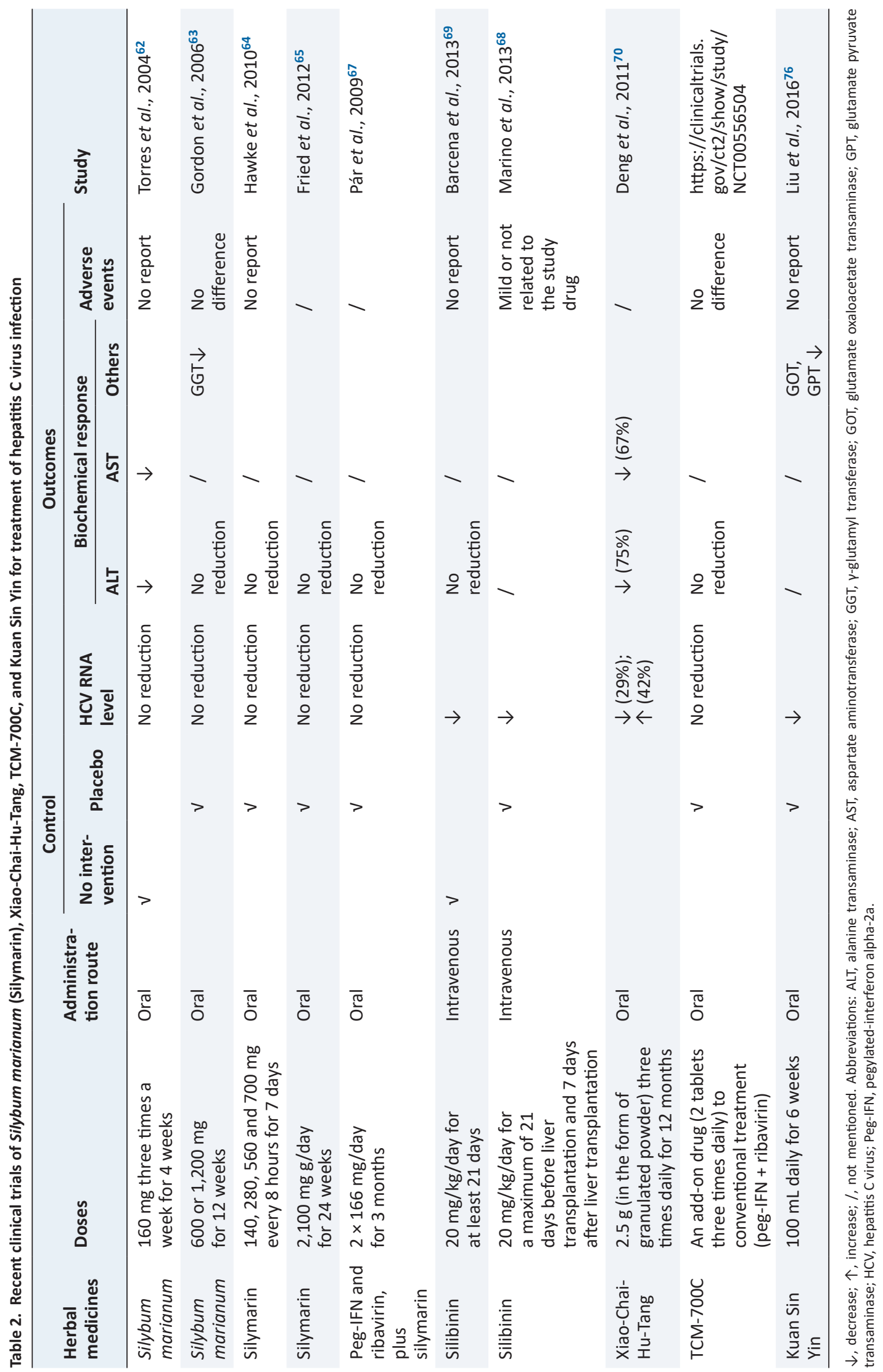


for preventing HCV replication. However, further research work is required to confirm the potent compounds and administration methods for the different herbs.

\section{Xiao-Chai-Hu-Tang}

Deng et $a l .{ }^{70}$ reported a single-arm phase II study evaluating the clinical efficacy of a traditional herbal formulation, Xiao-ChaiHu-Tang (XCHT; Sho-Sai-Ko-To or Sho-Saiko-To in Japan and So-Shi-Ho-Tang in Korea) in the treatment of CHC in patients not suitable for IFN-based therapy. The results showed that ALT and AST were decreased in $75 \%$ and $67 \%$ of patients, respectively, and biopsy histology scores improved in $38 \%$ of patients. HCV viral load decreased in $29 \%$ but increased in $42 \%$ of patients. These findings suggest that XCHT may improve liver pathology in CHC patients, but its antiviral activity remains undetermined. Recently, a phase II single-arm, open-label trial to determine the effects of Sho-Saiko-To on hepatic injury in patients with CHC was completed. In this trial, improvement of 2 points or greater as per Knodell's histology activity index scores in paired comparisons of pre- and postliver biopsy is defined as response, and no ALT or AST data were exhibited. The outcome was not bracing. Only 5 out of 24 patients $(20.8 \%)$ responded to the treatment. SAEs and other AEs were reported in $3(12.5 \%)$ and in $14(58.3 \%)$ of the patients, respectively. The data were updated at https://clinicaltrials.gov/ct2/ show/results/NCT00590564 on January 15, 2016, but have not yet been published officially. According to the moderate performance of XCHT, it should not be considered as the first-line treatment in $\mathrm{CHC}$ patients.

\section{TCM-700C}

Compound Codyceps-TCM-700C is an herbal preparation that has been shown to be potently hepatoprotective..$^{71}$ A phase II trial was conducted to detect the effects of adding TCM-700C onto the standard combination treatment for patients with genotype 1 HCV infection. This study was completed in May 2012. Based on the data updated at the https://clinicaltrials.gov/ct2/show/study/ NCT00556504 on August 7, 2014, there appeared to be no differences in SVR, virological response, and ALT response between regimens with and those without TCM-700C. SAEs were reported in $22.0 \%(9 / 41)$ and $14.3 \%(6 / 42)$ of patients with and those without TCM-700C, respectively.

\section{Kuan Sin Yin (KSY)}

Taipei City Hospital, Taiwan, conducted a phase II-III randomized, double-blinded and placebo-controlled trial to examine whether the Chinese herbal formula KSY is effective in HCV carriers with abnormal liver function. The results showed that 6 weeks of treatment with KSY significantly reduced HCV viral load, and ALT and AST levels were obviously decreased. ${ }^{72}$ Although KSY is not effective enough to gain SVR, it shows effective hepatoprotection for $\mathrm{CHC}$ patients. However, the long-term effects of KSY still remain to be evaluated in the future.

\section{Current critical issues and hurdles, and future perspectives}

Thus far, a great deal of preclinical studies on the anti-HCV effects of herbal medicines have been conducted, demonstrating great ef- fectiveness in vitro. However, only a few clinical trials with high methodological quality have been conducted, resulting in inconclusive findings for clinical efficacy. Thus, the exploratory journey from bench to bedside still has a long way to go. As such, the question then is, what are the critical issues and hurdles currently existing in the journey and the future perspectives?

First, different from western medicine, Chinese herbalism is based on concepts of holism and syndrome differentiation. The onset of sickness is considered as the imbalance of Yin and Yang, leading to miscellaneous symptoms in the course of disease. ${ }^{73}$ Herbal physicians treat patients as a whole and prescribe individual formulas based on the different body habitus. However, in the clinical trials, the interventions for all the patients recruited are the same, regardless of the different body habitus, contradicting the therapeutic pillars of Chinese herbalism. It would probably shed new light on the clinical trials of herbal medicines if the patients were to be given interventions according to their body habitus; although, this practice is hard to achieve in RCTs, which are conducted according to the approaches of western medicine.

Second, for formulation selection, herbal physicians obey the principle that the selected herbs are able to work in a complementary way with other herbs in the formulas, which could improve efficacy and reduce AEs. ${ }^{74,75}$ It is difficult to identify the actually acting compounds in the formulas. Moreover, after consumption, the herbs are metabolized in the liver, resulting in transformation of the bioactive compounds. Therefore, it is necessary to clearly define which is the "protagonist" (the naïve compound or the transformative compound) that exhibits anti-HCV activities. To achieve this, more animal experiments are required. However, currently, the ideal animal models for anti-HCV study are rare, which restricts the conduct of animal experiments. Further research is required to develop an ideal $\mathrm{HCV}$ animal model for anti-HCV study. Using such an HCV animal model would be of help to identify the actual acting compounds in the herbal medicines and determine the administration methods, which would contribute to the improvement of clinical efficacy and safety in clinical trials.

\section{Conclusions}

Despite apparent anti-HCV activities in vitro, clinical efficacy and safety of herbal medicines for the treatment of HCV infection have not been revealed convincingly. More animal studies in ideal models and well-designed clinical trials with larger sample sizes and longer treatment periods, taking the body habitus into consideration, are required to further assess the efficacy and safety of herbal medicines for HCV infection. Therefore, the exploratory journey towards treating $\mathrm{HCV}$ infections with herbal medicines, from bench to bedside, still has a long way to go.

\section{Acknowledgments}

This paper was supported by the Traditional Chinese Medicine Bureau of Guangdong Province (No. 20151283, to XY Yang) and the Department of Education of Guangdong Province (No. 2018GKTSCX033, to XY Yang).

\section{Conflict of interest}

The authors have no conflict of interests related to this publication. 
Author contributions

Manuscript writing (XYY, YYZ), supports of administration or intellectual content (WRX, SHH, LHW, XXH), and review design and critical revision of the manuscript (HHX).

\section{References}

[1] Ashraf MU, Iman K, Khalid MF, Salman HM, Shafi T, Rafi M, et al. Evolution of efficacious pangenotypic hepatitis $C$ virus therapies. Med Res Rev 2019;39:1091-1136. doi:10.1002/med.21554.

[2] Shire NJ, Sherman KE. Epidemiology of hepatitis C virus: A battle on new frontiers. Gastroenterol Clin North Am 2015;44:699-716. doi:10.1016/j.gtc.2015.07.002.

[3] Wong MCS, Huang JLW, George J, Huang J, Leung C, Eslam M, et al. The changing epidemiology of liver diseases in the Asia-Pacific region. Nat Rev Gastroenterol Hepatol 2019;16:57-73. doi:10.1038/ s41575-018-0055-0.

[4] Lim SG, Aghemo A, Chen PJ, Dan YY, Gane E, Gani R, et al. Management of hepatitis $C$ virus infection in the Asia-Pacific region: an update. Lancet Gastroenterol Hepatol 2017;2:52-62. doi:10.1016/ s2468-1253(16)30080-2.

[5] Dong Y, Chen H, Gao J, Liu Y, Li J, Wang J. Bioactive ingredients in Chinese herbal medicines that target non-coding RNAs: Promising new choices for disease treatment. Front Pharmacol 2019;10:515. doi:10.3389/fphar.2019.00515.

[6] Parvez MK, Arbab AH, Al-Dosari MS, Al-Rehaily AJ. Antiviral natural products against chronic hepatitis B: Recent developments. Curr Pharm Des 2016;22:286-293. doi:10.2174/13816128226661511121 52733.

[7] Hsueh TP, Lin WL, Tsai TH. Pharmacokinetic interactions of herbal medicines for the treatment of chronic hepatitis. J Food Drug Anal 2017;25:209-218. doi:10.1016/j.jfda.2016.11.010.

[8] Khonche A, Huseini HF, Gholamian M, Mohtashami R, Nabati F, Kianbakht S. Standardized Nigella sativa seed oil ameliorates hepatic steatosis, aminotransferase and lipid levels in non-alcoholic fatty liver disease: A randomized, double-blind and placebo-controlled clinical trial. J Ethnopharmacol 2019;234:106-111. doi:10.1016/j. jep.2019.01.009.

[9] Gheibi S, Gouvarchin Ghaleh HE, Motlagh BM, Azarbayjani AF, Zarei L. Therapeutic effects of curcumin and ursodexycholic acid on non-alcoholic fatty liver disease. Biomed Pharmacother 2019;115:108938. doi:10.1016/j.biopha.2019.108938.

[10] Li Q, Li HJ, Xu T, Du H, Huan Gang CL, Fan G, et al. Natural medicines used in the traditional Tibetan medical system for the treatment of liver diseases. Front Pharmacol 2018;9:29. doi:10.3389/ fphar.2018.00029.

[11] Guan MJ, Zhao N, Xie KQ, Zeng T. Hepatoprotective effects of garlic against ethanol-induced liver injury: A mini-review. Food Chem Toxicol 2018;111:467-473. doi:10.1016/j.fct.2017.11.059.

[12] Tsai FJ, Cheng CF, Chen CJ, Lin CY, Wu YF, Li TM, et al. Effects of Chinese herbal medicine therapy on survival and hepatic outcomes in patients with hepatitis $C$ virus infection in Taiwan. Phytomedicine 2018;57:30-38. doi:10.1016/j.phymed.2018.09.237.

[13] Alazard-Dany N, Denolly S, Boson B, Cosset FL. Overview of HCV life cycle with a special focus on current and possible future antiviral targets. Viruses 2019;11(1):30. doi:10.3390/v11010030.

[14] Park SB, Boyer A, Hu Z, Le D, Liang TJ. Discovery and characterization of a novel HCV inhibitor targeting the late stage of HCV life cycle. Antivir Ther (Lond) 2019. doi:10.3851/imp3303.

[15] Chigbu DI, Loonawat R, Sehgal M, Patel D, Jain P. Hepatitis C virus infection: Host-virus interaction and mechanisms of viral persistence. Cells 2019;8(4):376. doi:10.3390/cells8040376.

[16] Fried MW, Shiffman ML, Reddy KR, Smith C, Marinos G, Goncales FL $J r$, et al. Peginterferon alfa-2a plus ribavirin for chronic hepatitis $C$ virus infection. N Engl J Med 2002;347:975-982. doi:10.1056/NEJMoa020047.

[17] Manns MP, McHutchison JG, Gordon SC, Rustgi VK, Shiffman M, Rein- dollar $\mathrm{R}$, et al. Peginterferon alfa-2b plus ribavirin compared with interferon alfa- $2 b$ plus ribavirin for initial treatment of chronic hepatitis C: A randomised trial. Lancet 2001;358:958-965.

[18] Casey LC, Lee WM. Hepatitis C virus therapy update 2013. Curr Opin Gastroenterol 2013;29:243-249. doi:10.1097/MOG.0b013 e32835ff972.

[19] Werner CR, Franz C, Egetemeyr DP, Beck R, Malek NP, Lauer UM, et al. First-generation protease inhibitor-triple therapy: SVR 24, safety, and predictors of response in a large single center cohort. Virol J 2015;12:37. doi:10.1186/s12985-015-0261-0.

[20] European Association for the Study of the Liver. Electronic address eee. EASL recommendations on treatment of hepatitis C 2016. J Hepatol 2017;66:153-194. doi:10.1016/j.jhep.2016.09.001.

[21] European Association for the Study of the Liver. Electronic address eee, European Association for the Study of the L. EASL recommendations on treatment of hepatitis C 2018. J Hepatol 2018;69:461-511. doi:10.1016/j.jhep.2018.03.026.

[22] Pawlotsky JM. The end of the hepatitis $C$ burden: Really? Hepatology 2016;64:1404-1407. doi:10.1002/hep.28758.

[23] Hussein G, Miyashiro H, Nakamura N, Hattori M, Kakiuchi N, Shimotohno K. Inhibitory effects of sudanese medicinal plant extracts on hepatitis C virus (HCV) protease. Phytother Res 2000;14:510-516.

[24] Ravikumar YS, Ray U, Nandhitha M, Perween A, Raja Naika H, Khanna $\mathrm{N}$, et al. Inhibition of hepatitis $\mathrm{C}$ virus replication by herbal extract: Phyllanthus amarus as potent natural source. Virus Res 2011;158:8997. doi:10.1016/j.virusres.2011.03.014.

[25] Bachmetov L, Gal-Tanamy M, Shapira A, Vorobeychik M, GitermanGalam T, Sathiyamoorthy $\mathrm{P}$, et al. Suppression of hepatitis $\mathrm{C}$ virus by the flavonoid quercetin is mediated by inhibition of NS3 protease activity. J Viral Hepat 2012;19:e81-e88. doi:10.1111/j.13652893.2011.01507.x.

[26] Zuo G, Li Z, Chen L, Xu X. Activity of compounds from Chinese herbal medicine Rhodiola kirilowii (Regel) Maxim against HCV NS3 serine protease. Antiviral Res 2007;76:86-92. doi:10.1016/j.antiviral.2007.06.001.

[27] Zuo GY, Li ZQ, Chen LR, Xu XJ. In vitro anti-HCV activities of Saxifraga melanocentra and its related polyphenolic compounds. Antivir Chem Chemother 2005;16:393-398. doi:10.1177/095632020501600606.

[28] Chen SR, Wang AQ, Lin LG, Qiu HC, Wang YT, Wang Y. In vitro study on anti-hepatitis C virus activity of Spatholobus suberectus Dunn. Molecules 2016;21(10):1367. doi:10.3390/molecules21101367.

[29] Duan D, Li Z, Luo H, Zhang W, Chen L, Xu X. Antiviral compounds from traditional Chinese medicines Galla Chinese as inhibitors of HCV NS3 protease. Bioorg Med Chem Lett 2004;14:6041-6044. doi:10.1016/j. bmcl.2004.09.067.

[30] Lan KH, Wang YW, Lee WP, Lan KL, Tseng SH, Hung LR, et al. Multiple effects of Honokiol on the life cycle of hepatitis C virus. Liver Int 2012;32:989-997. doi:10.1111/j.1478-3231.2011.02621.x.

[31] Javed T, Ashfaq UA, Riaz S, Rehman S, Riazuddin S. In-vitro antiviral activity of Solanum nigrum against Hepatitis C Virus. Virol J 2011;8:26. doi:10.1186/1743-422X-8-26.

[32] Kong L, Li S, Liao Q, Zhang Y, Sun R, Zhu X, et al. Oleanolic acid and ursolic acid: Novel hepatitis $C$ virus antivirals that inhibit NS5B activity. Antiviral Res 2013;98:44-53. doi:10.1016/j.antiviral.2013.02.003.

[33] Lin CW, Lo CW, Tsai CN, Pan TC, Chen PY, Yu MJ. Aeginetia indica decoction inhibits hepatitis C virus life cycle. Int J Mol Sci 2018;19(1):208. doi:10.3390/ijms19010208.

[34] Ashfaq UA, Jalil A, UI Qamar MT. Antiviral phytochemicals identification from Azadirachta indica leaves against HCV NS3 protease: An in silico approach. Nat Prod Res 2016;30:1866-1869. doi:10.1080/147 86419.2015.1075527.

[35] Polyak SJ, Morishima C, Shuhart MC, Wang CC, Liu Y, Lee DY. Inhibition of T-cell inflammatory cytokines, hepatocyte NF-kappaB signaling, and HCV infection by standardized Silymarin. Gastroenterology 2007;132:1925-1936. doi:10.1053/j.gastro.2007.02.038.

[36] Lin LT, Chung CY, Hsu WC, Chang SP, Hung TC, Shields J, et al. Saikosaponin b2 is a naturally occurring terpenoid that efficiently inhibits hepatitis C virus entry. J Hepatol 2015;62:541-548. doi:10.1016/j. jhep.2014.10.040.

[37] Ratnoglik SL, Aoki C, Sudarmono P, Komoto M, Deng L, Shoji I, et al. Antiviral activity of extracts from Morinda citrifolia leaves and 
chlorophyll catabolites, pheophorbide a and pyropheophorbide a, against hepatitis C virus. Microbiol Immunol 2014;58:188-194. doi:10.1111/1348-0421.12133.

[38] Hung TC, Jassey A, Lin CJ, Liu CH, Lin CC, Yen MH, et al. Methanolic extract of Rhizoma Coptidis inhibits the early viral entry steps of hepatitis C virus infection. Viruses 2018;10(12):669. doi:10.3390/ v10120669.

[39] Qian XJ, Zhang XL, Zhao P, Jin YS, Chen HS, Xu QQ, et al. A schisandraderived compound schizandronic acid inhibits entry of Pan-HCV genotypes into human hepatocytes. Sci Rep 2016;6:27268. doi:10.1038/ srep27268.

[40] Yu F, Wang Q, Zhang Z, Peng Y, Qiu Y, Shi Y, et al. Development of oleanane-type triterpenes as a new class of HCV entry inhibitors. J Med Chem 2013;56:4300-4319. doi:10.1021/jm301910a.

[41] Calland N, Sahuc ME, Belouzard S, Pene V, Bonnafous P, Mesalam AA, et al. Polyphenols inhibit hepatitis $C$ virus entry by a new mechanism of action. J Virol 2015;89:10053-10063. doi:10.1128/jvi.01473-15.

[42] Lee WP, Lan KL, Liao SX, Huang YH, Hou MC, Lan KH. Inhibitory effects of amentoflavone and orobol on daclatasvir-induced resistance-associated variants of hepatitis C virus. Am J Chin Med 2018;46:835852. doi:10.1142/s0192415x18500441.

[43] Oyero OG, Toyama M, Mitsuhiro N, Onifade AA, Hidaka A, Okamoto $M$, et al. Selective inhibition of hepatitis $C$ virus replication by alphazam, a Nigella sativa seed formuliation. Afr J Tradit Complement Altern Med 2016;13:144-148. doi:10.21010/ajtcam.v13i6.20.

[44] Li S, Kodama EN, Inoue Y, Tani H, Matsuura Y, Zhang J, et al. Procyanidin B1 purified from Cinnamomi cortex suppresses hepatitis $C$ virus replication. Antivir Chem Chemother 2010;20:239-248. doi:10.3851/ imp1597.

[45] Althagafy HS, Graf TN, Sy-Cordero AA, Gufford BT, Paine MF, Wagoner $\mathrm{J}$, et al. Semisynthesis, cytotoxicity, antiviral activity, and drug interaction liability of 7-O-methylated analogues of flavonolignans from milk thistle. Bioorg Med Chem 2013;21:3919-3926. doi:10.1016/j. bmc.2013.04.017.

[46] Ho TY, Wu SL, Lai IL, Cheng KS, Kao ST, Hsiang CY. An in vitro system combined with an in-house quantitation assay for screening hepatitis $C$ virus inhibitors. Antiviral Res 2003;58:199-208.

[47] Ashfaq UA, Masoud MS, Nawaz Z, Riazuddin S. Glycyrrhizin as antiviral agent against Hepatitis C Virus. J Transl Med 2011;9:112. doi:10.1186/1479-5876-9-112.

[48] Elsebai MF, Koutsoudakis G, Saludes V, Perez-Vilaro G, Turpeinen A, Mattila S, et al. Pan-genotypic hepatitis $C$ virus inhibition by batural products derived from the wild Egyptian Artichoke. J Virol 2016;90:1918-1930. doi:10.1128/jvi.02030-15.

[49] Lee S, Yoon KD, Lee M, Cho Y, Choi G, Jang H, et al. Identification of a resveratrol tetramer as a potent inhibitor of hepatitis $C$ virus helicase. Br J Pharmacol 2016;173:191-211. doi:10.1111/bph.13358.

[50] Ma JN, Bolraa S, Ji M, He QQ, Ma CM. Quantification and antioxidant and anti-HCV activities of the constituents from the inflorescences of Scabiosa comosa and S. tschilliensis. Nat Prod Res 2016;30:590-594. doi:10.1080/14786419.2015.1027701.

[51] Manvar D, Mishra M, Kumar S, Pandey VN. Identification and evaluation of anti hepatitis $\mathrm{C}$ virus phytochemicals from Eclipta alba. J Ethnopharmacol 2012;144:545-554. doi:10.1016/j.jep.2012.09.036.

[52] Elsebai MF, Abass K, Hakkola J, Atawia AR, Farag MA. The wild Egyptian artichoke as a promising functional food for the treatment of hepatitis C virus as revealed via UPLC-MS and clinical trials. Food Funct 2016;7:3006-3016. doi:10.1039/c6fo00656f.

[53] Tang ZM, Peng M, Zhan CJ. [Screening 20 Chinese herbs often used for clearing heat and dissipating toxin with nude mice model of hepatitis $C$ viral infection]. Zhongguo Zhong Xi Yi Jie He Za Zhi 2003;23:447-448.

[54] Shikov AN, Djachuk GI, Sergeev DV, Pozharitskaya ON, Esaulenko EV, Kosman VM, et al. Birch bark extract as therapy for chronic hepatitis C-a pilot study. Phytomedicine 2011;18:807-810. doi:10.1016/j. phymed.2011.01.021.

[55] Seeff LB, Curto TM, Szabo G, Everson GT, Bonkovsky HL, Dienstag JL, et al. Herbal product use by persons enrolled in the hepatitis C Antiviral Long-Term Treatment Against Cirrhosis (HALT-C) Trial. Hepatology 2008;47:605-612. doi:10.1002/hep.22044.

[56] Tusenius KJ, Spoek AM, van Hattum J. Exploratory study on the ef- fects of treatment with two mistletoe preparations on chronic hepatitis C. Arzneimittelforschung. 2005;55:749-753. doi:10.1055 /s-0031-1296925.

[57] Freedman ND, Curto TM, Morishima C, Seeff LB, Goodman ZD, Wright EC, et al. Silymarin use and liver disease progression in the Hepatitis C Antiviral Long-Term Treatment against Cirrhosis trial. Aliment Pharmacol Ther 2011;33:127-137. doi:10.1111/j.13652036.2010.04503.x.

[58] Sho Y, Fujisaki K, Sakashita H, Yamaguchi K, Tahara K, Kubozono O, et al. Orally administered Kampo medicine, Juzen-taiho-to, ameliorates anemia during interferon plus ribavirin therapy in patients with chronic hepatitis C. J Gastroenterol. 2004;39:1202-1204. doi:10.1007/s00535-004-1472-0.

[59] Kainuma M, Hikiami H, Nozaki K, Hayashi K, Shimada Y, Terasawa K. The effect of a herbal medicine (Mao-to) for the prevention of interferon-induced psychiatric complications in chronic hepatitis C: A pilot study. Hum Psychopharmacol 2004;19:235-241. doi:10.1002/ hup. 587.

[60] Qin XK, Han M, Liu JP. [Compound Chinese herbal medicines, Chinese herbal drugs and their active extracts for treatment of chronic hepatitis C: a systematic review and meta-analysis of randomized clinical trials]. Zhong Xi Yi Jie He Xue Bao 2009;7:913-928. doi:10.3736/ jcim20091003.

[61] Zhao S, Liu E, Wei K, Lu S, Chu Y, Li Y, et al. Interferon plus Chinese herbs are associated with higher sustained virological response than interferon alone in chronic Hepatitis C: A meta-analysis of randomised trials. Antiviral Res 2011;89:156-164. doi:10.1016/j.antiviral.2010.12.003.

[62] Torres M, Rodriguez-Serrano F, Rosario DJ, Rodriguez-Perez F, Toro $\mathrm{DH}$. Does Silybum marianum play a role in the treatment of chronic hepatitis C? P R Health Sci J 2004;23:69-74.

[63] Gordon A, Hobbs DA, Bowden DS, Bailey MJ, Mitchell J, Francis AJ, et al. Effects of Silybum marianum on serum hepatitis $C$ virus RNA, alanine aminotransferase levels and well-being in patients with chronic hepatitis C. J Gastroenterol Hepatol. 2006;21:275-280. doi:10.1111/ j.1440-1746.2006.04138.x

[64] Hawke RL, Schrieber SJ, Soule TA, Wen Z, Smith PC, Reddy KR, et al. Silymarin ascending multiple oral dosing phase I study in noncirrhotic patients with chronic hepatitis C. J Clin Pharmacol. 2010;50:434-449. doi:10.1177/0091270009347475.

[65] Fried MW, Navarro VJ, Afdhal N, Belle SH, Wahed AS, Hawke RL, et al. Effect of silymarin (milk thistle) on liver disease in patients with chronic hepatitis $C$ unsuccessfully treated with interferon therapy: $A$ randomized controlled trial. JAMA 2012;308:274-282. doi:10.1001/ jama.2012.8265.

[66] Yang Z, Zhuang L, Lu Y, Xu Q, Chen X. Effects and tolerance of silymarin (milk thistle) in chronic hepatitis $C$ virus infection patients: A meta-analysis of randomized controlled trials. Biomed Res Int 2014;2014:941085. doi:10.1155/2014/941085.

[67] Par A, Roth E, Miseta A, Hegedus G, Par G, Hunyady B, et al. [Effects of supplementation with the antioxidant flavonoid, silymarin, in chronic hepatitis $C$ patients treated with peg-interferon + ribavirin. A placebo-controlled double blind study]. Orv Hetil 2009;150:73-79. doi:10.1556/oh.2009.28517.

[68] Marino Z, Crespo G, D’Amato M, Brambilla N, Giacovelli G, Rovati L, et al. Intravenous silibinin monotherapy shows significant antiviral activity in HCV-infected patients in the peri-transplantation period. J Hepatol 2013;58:415-420. doi:10.1016/j.jhep.2012.09.034.

[69] Barcena R, Moreno A, Rodriguez-Gandia MA, Albillos A, Arocena C, Blesa $\mathrm{C}$, et al. Safety and anti-HCV effect of prolonged intravenous silibinin in HCV genotype 1 subjects in the immediate liver transplant period. J Hepatol 2013;58:421-426. doi:10.1016/j.jhep.2012.10.009.

[70] Deng G, Kurtz RC, Vickers A, Lau N, Yeung KS, Shia J, et al. A single arm phase II study of a Far-Eastern traditional herbal formulation (sho-sai-ko-to or xiao-chai-hu-tang) in chronic hepatitis C patients. J Ethnopharmacol 2011;136:83-87. doi:10.1016/j.jep.2011.04.008.

[71] Ko WS, Hsu SL, Chyau CC, Chen KC, Peng RY. Compound Cordyceps TCM-700C exhibits potent hepatoprotective capability in animal model. Fitoterapia 2010;81:1-7. doi:10.1016/j.fitote.2009.06.018.

[72] Liu CY, Ko PH, Yen HR, Cheng CH, Li YH, Liao ZH, et al. The Chinese medicine Kuan-Sin-Yin improves liver function in patients with chron- 
J Explor Res Pharmacol

ic hepatitis C: A randomised and placebo-controlled trial. Complement Ther Med 2016;27:114-122. doi:10.1016/j.ctim.2016.06.004.

[73] Zhang L, Schuppan D. Traditional Chinese Medicine (TCM) for fibrotic liver disease: hope and hype. J Hepatol 2014;61:166-168. doi:10.1016/j.jhep.2014.03.009.

[74] Zhang L, Wang G, Hou W, Li P, Dulin A, Bonkovsky HL. Contemporary clinical research of traditional Chinese medicines for chronic hepatitis B in China: An analytical review. Hepatology 2010;51:690-698.
Yang XY. et al: Herbals for hepatitis C virus infection doi:10.1002/hep.23384.

[75] Vickers A, Zollman C. ABC of complementary medicine: Herbal medicine. BMJ 1999;319:1050-1053.

[76] Liu CY, Ko PH, Yen HR, Cheng CH, Li YH, Liao ZH, et al. The Chinese medicine Kuan-Sin-Yin improves liver function in patients with chronic hepatitis C: A randomised and placebo-controlled trial. Complementary Therapies in Medicine 2016;27:114-122. doi:10.1016/j. ctim.2016.06.004. 